\title{
TIME SERIES MODELS FOR FORECASTING EXCHANGE RATES
}

\section{GIVI LEMONJAVA}

\author{
Associated Professor, \\ University of Georgia, Georgia \\ Givi@tbcbank.com.ge
}

KEYWORDS: EXCHANGE RATE, FORECASTING EXCHANGE RARE, TIME SERIES ANALYSIS, ARIMA, MOVING AVERAGE MODEL, SIMPLE AND DOUBLE EXPONENTIAL SMOOTHING MODELS.

For citation: Lemonjava, G. (2019). Time Series Models for Forecasting Exchange Rates, Globalization And Business, №8, pp. 149-160. https://doi.org/10.35945/gb.2019.08.020

\section{INTRODUCTION}

In a marketplace, money is a medium of exchange, where people interact and use money widely daily. To some extent many people make this place effective and efficient. An exchange rate represents the price of one currency in terms of another. It reflects the ratio at which one currency can be exchanged for another one. Exchange rates forecasting is a very important and challenging subject of finance market, especially after the Bretton Woods system of fixed exchange rate breakdown in 1973 and desirability of obtaining reliable forecasts of exchange rates became highly demanding to earn income from speculative activities, to determine optimal government policies as well as to make business decisions.This is important for all the firms which have their business spread over different countries or for those which raise funds in different currency. Business people mainly use exchange rates forecasting results in following types of decisions like choosing currency for invoicing, pricing transactions, borrowing and lending, and management of open currency positions. This market is the largest and the most liquid financial market, called as Forex Market,which includes all aspects of buying, selling and exchanging currencies at current or determined prices.The forex market is made up of banks, commercial companies, central banks, investment management firms, hedge funds, and retail forex brokers and investors. Forecasting the short-run fluctuations and direction of change of the currency exchange rates is important for all these participants. GEL is trading mainly in the local interbankmoney market which is integrated into the Bloomberg trading system. This market is small, and currency demand and supply is not very stable and lacks market efficiency. These factors give GEL currency some extent of instability and volatility.

Exchange rate can be forecasted by using structura models where exchange rate of a country has a relationship with money supply, output, inflation, interest rate, balance of payment etc. These explanatory variables are used to explain changes in exchange rate. However, there are several limitations which make this model less valuable in the field of finance. One such reason is that data for these macro- economic variables are available at the most on monthly basis, while in finance one needs to deal with very high frequency data such as daily, or even more frequent. To avoid these problems, one often uses models which attempt to predict financial variables using information contained only in their own past values and possibly current and past values of an error term. Time series models such as Moving Average (MA), Exponential Smoothing (ES) and ARIMA methodology can be used for estimating, checking and forecasting exchange rate.

The main goal of this study is to forecast future exchange rate trends by using currency rates time-series, representing past trends, patterns and waves. Moving average, exponential smoothing models and Auto Regressive Integrated Moving Average (ARIMA) are that class of models that are widely used in this field. We aim to use these models to estimate their predictability and compare their projected results in forecasting the GEL exchange rate against the USD. There is a tendency that GEL depreciates against USD and EUR (Figure 1). It has been following the inflation targeting regime, where exchange rate regime is floating -change of exchange rate is free.The official exchange rate of the Georgian GEL against the USD is calculated each business day. The official exchange rate of GEL against USD is calculated as the average weighted exchange rate of the registered spot trades on the interbank market functioning within the Bloomberg trade platform. Then, the official exchange rate of GEL against other foreign currencies is determined according to the rate on international markets on the basis of cross-currency exchange rates.

The National Bank of Georgia has intervention policy that mainly lasts for two years, shows policy leaning to accumulate FX reserves. Such policy has some risk, depending on changing circumstance, and may trigger of exchange rate depreciation trend or increase exchange rate volatility, or both. The shapes of data presented in Table 1 and plotted in the Figure 1 clearly indicates to such tendency, and it is obvious that these time series are not stationary. 


\section{GEL/USD and GEL/EUR Time Series Plots}

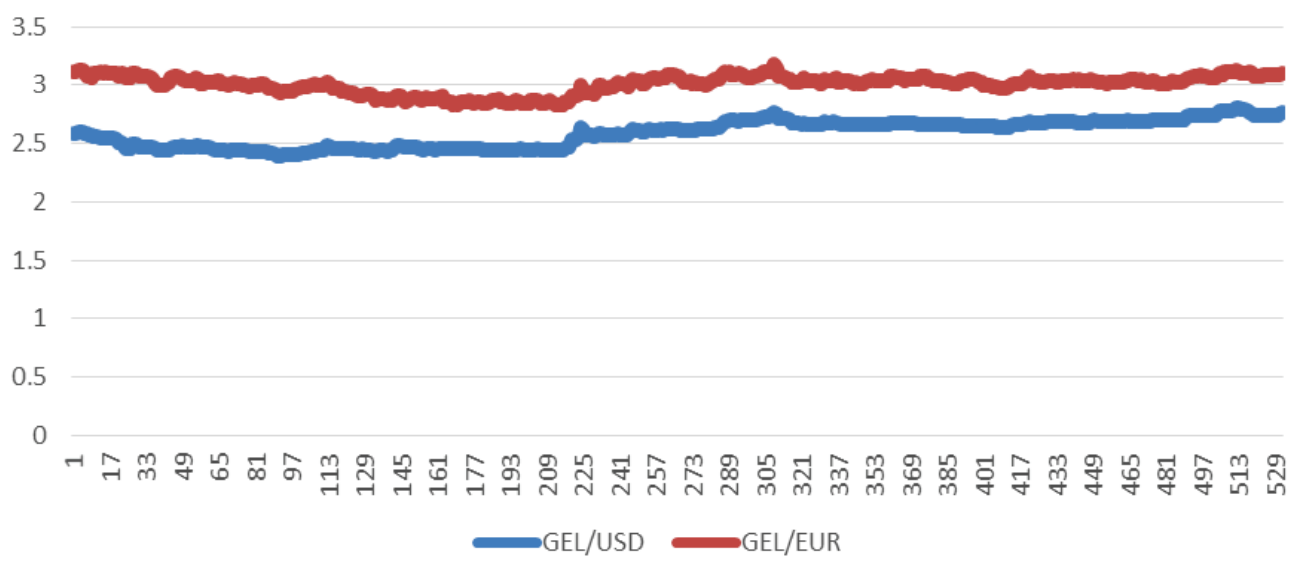

Figure 1

Table 1: Descriptive Statistics for the Variables

\begin{tabular}{|l|r|r|r|r|r|r|r|}
\hline Variable & Mean & Median & StDev & Min & Max & Skewness & Kurtosis \\
\hline GEL/EUR & 3,00851 & 3,0286 & 0,07722 & 3,0286 & 3,1766 & $-0,79958$ & $-0,25307$ \\
\hline GEL/USD & 2,58599 & 2,6184 & 0,11432 & 2,6184 & 2,8023 & $-0,14229$ & $-1,4857$ \\
\hline
\end{tabular}

Data sets used in this statistical analysis were extracted from the Georgian National Bank (www.nbq.gov.ge/index.php? $m=304$ / the section: Foreign Exchange Market) and include official trading rates for this market from the 1st of May 2018 to the $31^{\text {st }}$ of July.

\section{EXCHANGE RATE FORECASTING: TIME SERIES MODELS \\ A. Moving Average Model}

\section{Simple Moving Average (SMA)}

Sometimes there is real concern about recent observation. The Simple Moving Average (SMA) models simply compute mean of the predefined number of data points. Equation (1) represents the moving average of order $r, \operatorname{SMA}(r)$.

$$
\hat{Y}_{t+1}=\frac{\sum_{k=1}^{r} Y_{t-k+1}}{r}
$$

Where: $\hat{Y}_{t+1}$ the forecast value for the $\mathrm{t}+1$ period; $Y_{t}$ the actual value at period $\mathrm{t} ; \mathrm{r}=$ number of periods in moving average.

A SMA model is simple and averages the past data of time sires. There are two types of SMA models: (1) a short-run SMA (SRSMA), and (2) long run MA (LRSMA). The SRMA includes most recent currency prices, while LRSMA- a longer series of past currency prices. Combination of these two models may be used for generating a buy or sell foreign currency signal.

One common characteristicof all moving averages is that their exchange rate estimates almost always would be behind the real price. When exchange rate has tendency to go down, the simple moving average data remains above the real exchange rate, and, conversely, when the exchange rate is rising, SMA would most likely be lower. If both are not the case, in other words, there are no trends, or it is changing very frequently, moving average can give incorrect signals about exchange rate change directions. Because of all the data points in the SMA process are given equal weight, this method fails to reflect the importance of time ordering with respect to observations. Anothermethod, called weighted moving average, reflects this point.

\section{Weighted Moving Average (WMA)}

In WMA each previous currency price is multiplied by a weight factor. The weight factors are not the same and differs from day to day. The equation used in WMA is

$$
\hat{Y}_{t+1}=\sum_{i=1}^{r} \frac{r-i+1}{R} Y_{t-i}
$$


Where $R=\sum_{i=}^{r} i, \mathrm{r}=$ number of periods in moving average.

The weight factor in (2) decreases further back in time, and so the trend will be responsive to recent change.

\section{Exponential Moving Average (EMA)}

Moving average are lagging indicators. When currency rate is trending down, the average price of currency remains above the price; and conversely, the SMA's price would be below. The EMAs reduce the lag by applying more weight to recent prices relative to older prices. The EMA equation can be written as

$$
\hat{Y}_{t+1}=\left(Y_{t}-\hat{Y}_{t}\right) \omega+Y_{t}
$$

\section{Where}

$\omega=2 /(1+r), r=$ number of periods in moving average.

Exponential smoothing gives two times more weight to today's measurement than it would be in SMA.

\section{Results of SME, EMA, and WMA}

(1), (2) and (3)models were used for three periods moving average and their forecasted results are showed on Figure 2 and inTable 2. To evaluate these models weremade by calculatingthe metrics shown in Table 2 and 3 . As we see, the best model according MAD and MSE is MA (2), but by FCPCD ${ }^{1}$ is $A M(3)$.

Table 2: The Accuracy Measures of SMAand EMA Models

\begin{tabular}{|l|c|c|c|c|}
\hline & $\begin{array}{c}\text { SMA } \\
\text { GEL/USD }\end{array}$ & $\begin{array}{c}\text { SMA } \\
\text { GEL/EUR }\end{array}$ & $\begin{array}{c}\text { EMA } \\
\text { GEL/USD }\end{array}$ & $\begin{array}{c}\text { EMA } \\
\text { GEL/EUR }\end{array}$ \\
\hline MAPE & 0.00248 & 0.00416 & 0.001125 & 0.001877 \\
\hline MAD & 0.00639 & 0.01251 & 0.002907 & 0.005643 \\
\hline MSD & 0.00012 & 0.00029 & $2.6 \mathrm{E}-05$ & $6.05 \mathrm{E}-05$ \\
\hline FCPCD & $67 \%$ & $68 \%$ & $86 \%$ & $89 \%$ \\
\hline
\end{tabular}

Table 3: The Accuracy Measures of WMA Models

\begin{tabular}{|l|c|c|}
\hline & $\begin{array}{c}\text { WMA } \\
\text { GEL/USD }\end{array}$ & $\begin{array}{c}\text { WMA } \\
\text { GEL/EUR }\end{array}$ \\
\hline MAPE & 0.00215 & 0.00366 \\
\hline MAD & 0.00555 & 0.01099 \\
\hline MSD & 0.00010 & 0.00024 \\
\hline FCPCD & $66 \%$ & $68 \%$ \\
\hline
\end{tabular}

Figure 2: Forecasting with the MA for GEL/USD and GEL/EUR

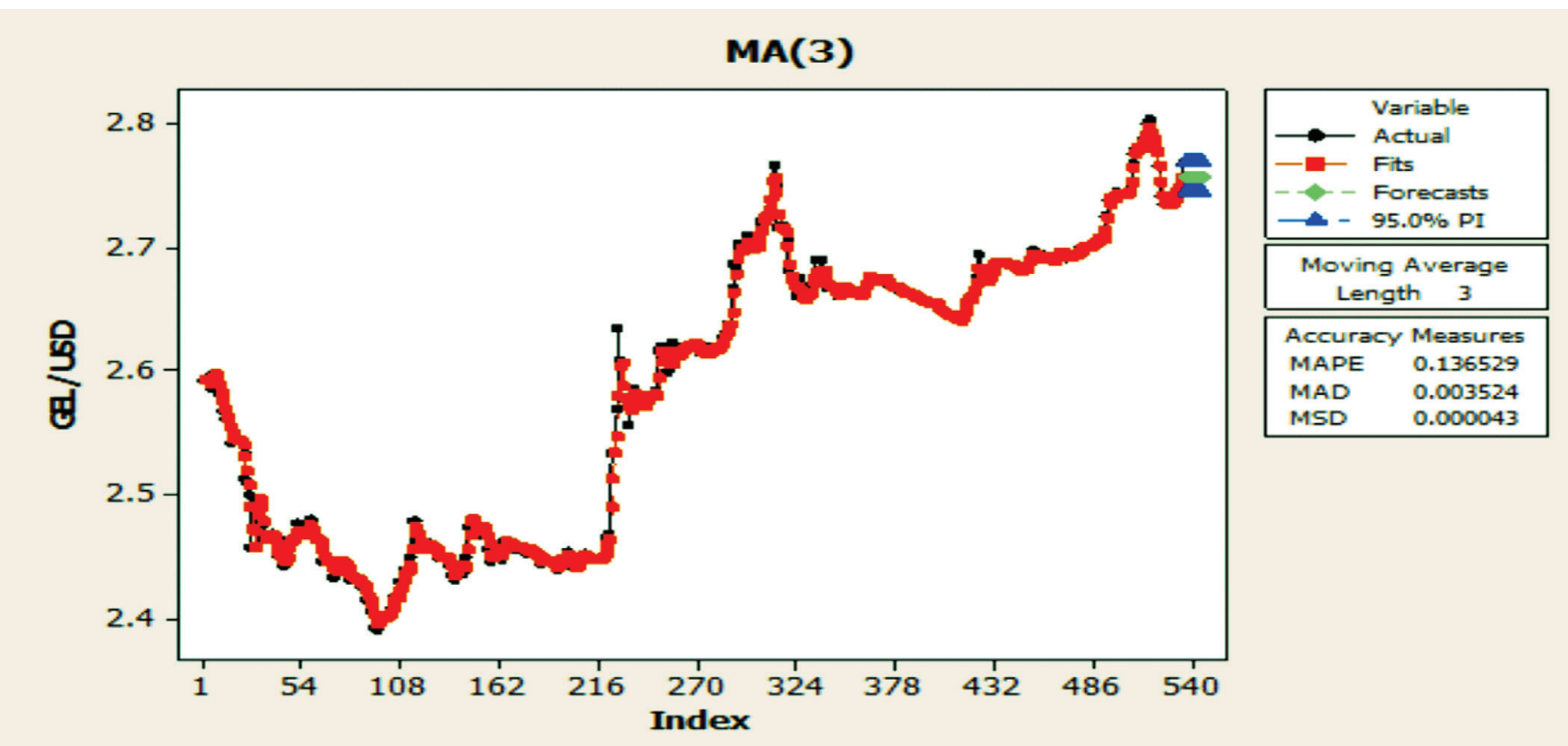

${ }^{1}$ The frequency of the correctpredicted direction of change by used models, for short 


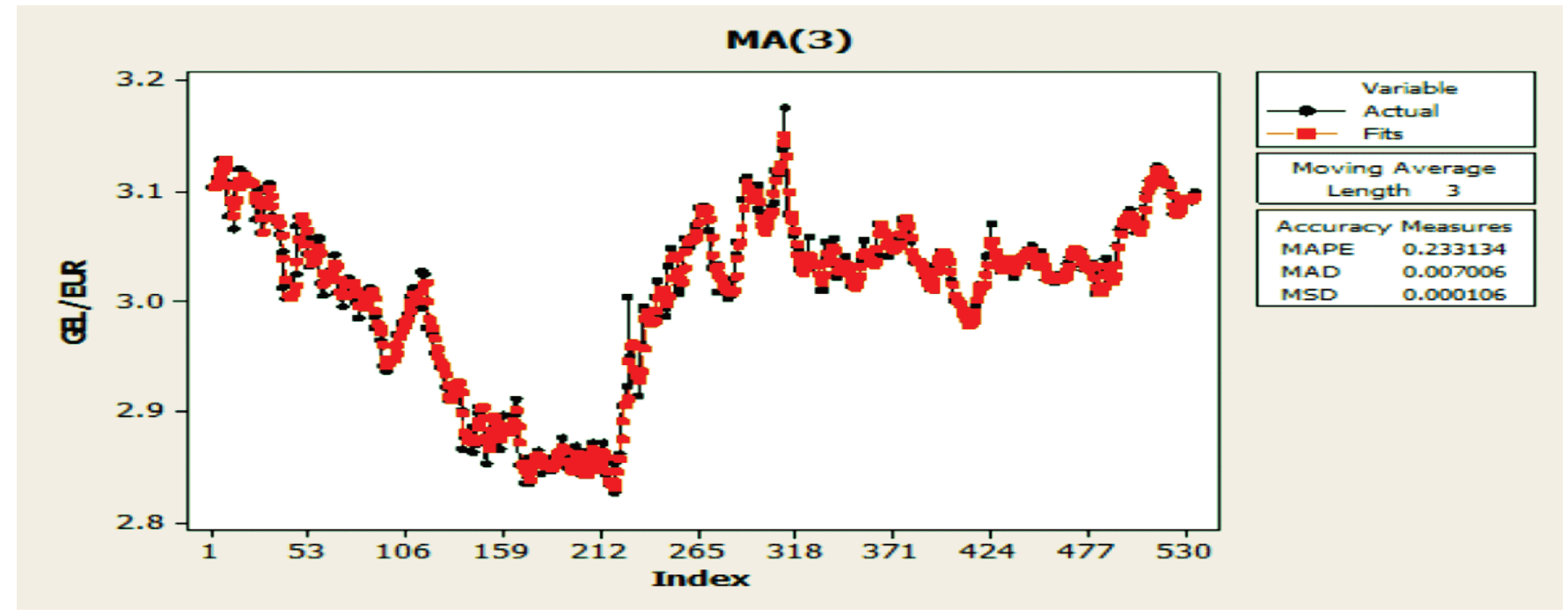

Figure 3: Autocorrelation Function for MA Residuals

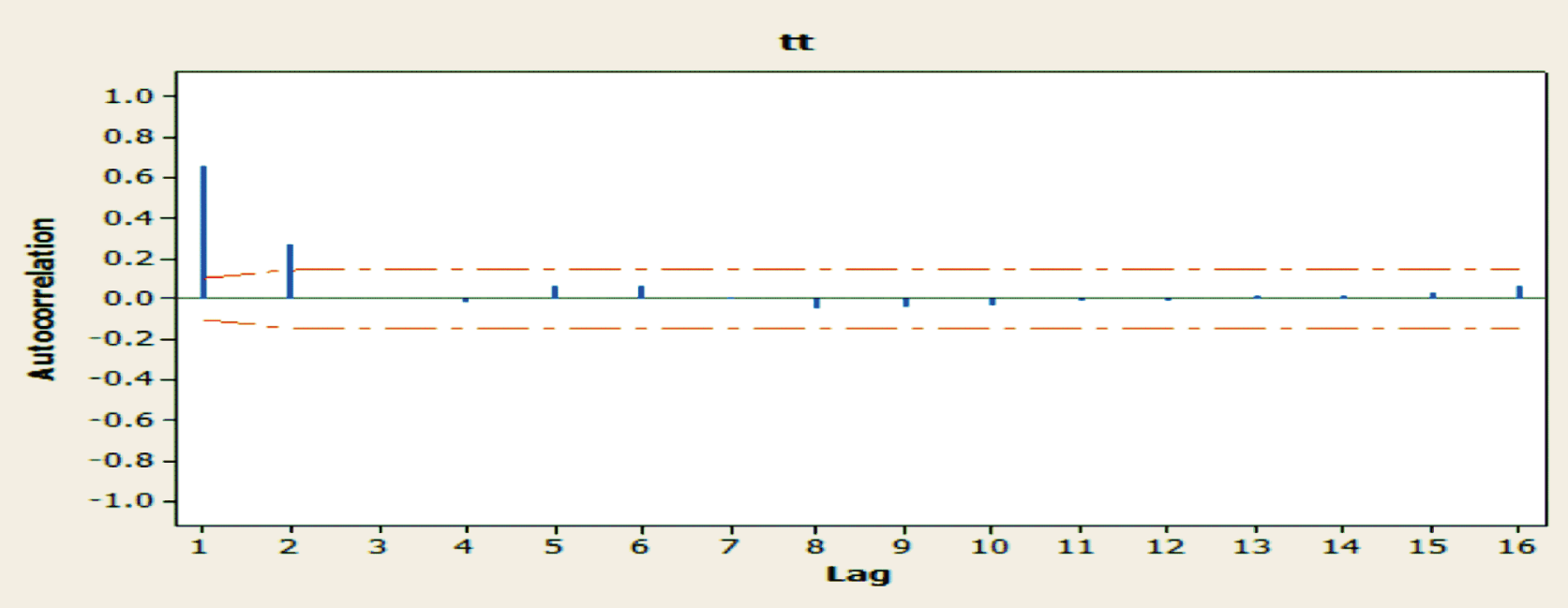

These three methods provide an efficient mechanism when time series is stationary. Almost all autocorrelation coefficients of these MA class models residuals have pattern showed by Figure 3, and this function is almost the same for all lengths of MA models. At the $95 \%$ confidence level we can say that none of these autocorrelation coefficients are significantly different from zero, except the first two.Approximately the same results were received for GEL/EUR time series. As we know, a plot of residuals versus fits is useful diagnostic tool. The ideal for this plot is a horizontal band of points. Figure 4 represents a plot of residuals versus predicted values from our estimated model. As this figures show, the residuals are plotted enough horizontally and do not indicate to serious problems.

Figure 4: Plot of Residuals
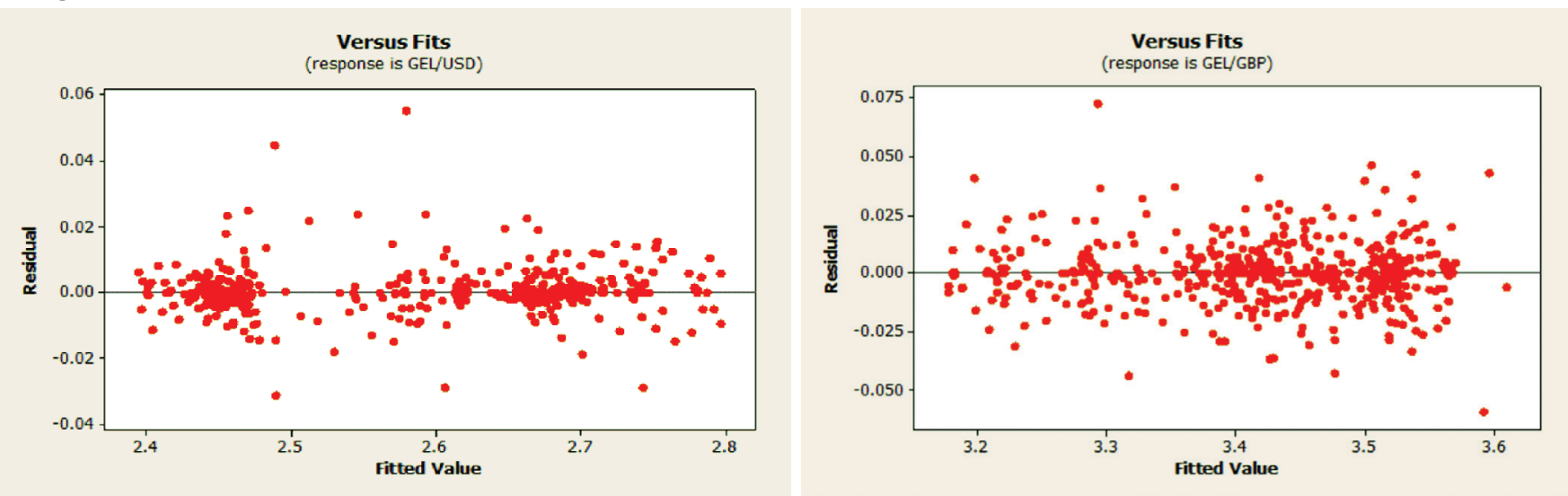


\section{B. SINGLE AND DOUBLE EXPONENTIAL SMOOTHING MODEL}

Exponential smoothing models are models that are the most widely used time series models in the fields of economics, finance and business analysis. According to these models the new forecasts are derived by adjusting plus a proportion of the last error. The simplest model is the single parameter exponential smoothing model which is, Next forecast $=$ Last forecast + A proportion of the last error.

This type of model is used for short-term forecasting where time-series data doesn't include predictable upward and down trends. Inthe following analysis, estimated values for $\alpha$ is within the range $-0<\alpha<1$ andestimation of parameters is done through calculation of values that minimize the sum of squared errors. Starting value for the calculation is always the mean of the observed series. In symbols, the single parameter model may be written as:

$$
\hat{Y}_{t+1}=\alpha Y_{t}+(1-\alpha) \hat{Y}_{t}, \text { or }
$$

$\hat{Y}_{t+1}=\hat{Y}_{t}+\alpha\left(Y_{t}-\hat{Y}_{t}\right)$

Equation (1) for timplies $\hat{Y}_{t}=\alpha Y_{t-1}+(1-\alpha) \hat{Y}_{t-1}$. Substitution this in equation (1) and continue it for $\hat{Y}_{t-1}$ and so forth gives

$$
\hat{Y}_{t+1}=\alpha Y_{t}+\alpha(1-\alpha) Y_{t-1}+\alpha(1-\alpha)^{2} Y_{t-2}+\cdots
$$

Assigning the value to $\alpha$ is the key aspect of this analysis. One method to choice $\alpha$ is iterative procedure that minimizes squared error (MSD). Forecasts are computed for, say, $\alpha=0.1,0.2, \ldots, 0.9$, and (MSD) computed for each $\alpha$. Lower weights produce amoother line, and higher weight produce a less smooth line. It is recommended to use smaller weight for noisy data so that the smoothed values do not fluctuate with the noise. The statistical software Minitab contains option to find out optimal $\alpha$ value that minimizes the sum of the squared residuals in an ARIMA (0, 1 , 1) model. The ARIMA $(0,1,1)$ model calculates the differences of the data and includes a moving average term of order 1. The simple exponential smoothing has a single level $(\alpha)$ parameter, equation (1) and (1), Holt's exponential smoothing has level $(\alpha)$ and trend $(\gamma)$ parameters, equations (6).

$$
\begin{aligned}
& L_{t}=\alpha Y_{t}+(1-\alpha)\left(L_{t-1}+T_{t-1}\right) \\
& T_{t}=\gamma\left(L_{t}-L_{t-1}\right)+(1-\gamma) T_{t-1} \\
& Y_{t+p}=L_{t}+p T_{t}
\end{aligned}
$$

Where:

$L_{t}=$ the smoothed value; $T_{t}=$ the trend estimate, $Y_{t}=$ the observaton in period $t$

$\hat{Y}_{t+p}=$ the forecast for $p$ periods int to the future, $\alpha$ and $\gamma=$ smoothing consant

The simple exponential smoothing models results are reported in Table 2 and 3. Using Minitab version 19, our calculationprocedure generates exponential smoothing models for GEL/USD and GEL/EUR exchange rate series. These models accuracy measures are also presented in Table 4. Holt's Double Exponential Smoothing's accuracy measures for all currencies are much better than the ones for the Simple Exponential Smoothing.

\section{Table 4: The Accuracy Measures of ExponentialSmoothing Models}

\begin{tabular}{|l|l|l|l|l|}
\hline & \multicolumn{2}{|l|}{ The Simple Exponential Smoothing (1) } & \multicolumn{2}{l|}{ Holt's Double Exponential Smoothing (3) } \\
\hline & GEL/USD & GEL/EUR & GEL/USD & GEL/EUR \\
\hline MAPE & 0.291009 & 0.456079 & 0.16721 & 0.319127 \\
\hline MAD & 0.007532 & 0.013717 & 0.004315 & 0.0096 \\
\hline MSD & 0.000162 & 0.000328 & 0.000067 & 0.000236 \\
\hline FCPCD (\%) & $75 \%$ & $65 \%$ & $77 \%$ & $69 \%$ \\
\hline
\end{tabular}

Figure 6 presents ACF for exponential smoothing models residuals plots. As we can see, there are no significant autocorrelation pattern in the ACFs. We also tested the Winters' models but it turned out that the seasonal component in our time series was not significant. 
Figure 5: ACF Plot for SES and HES
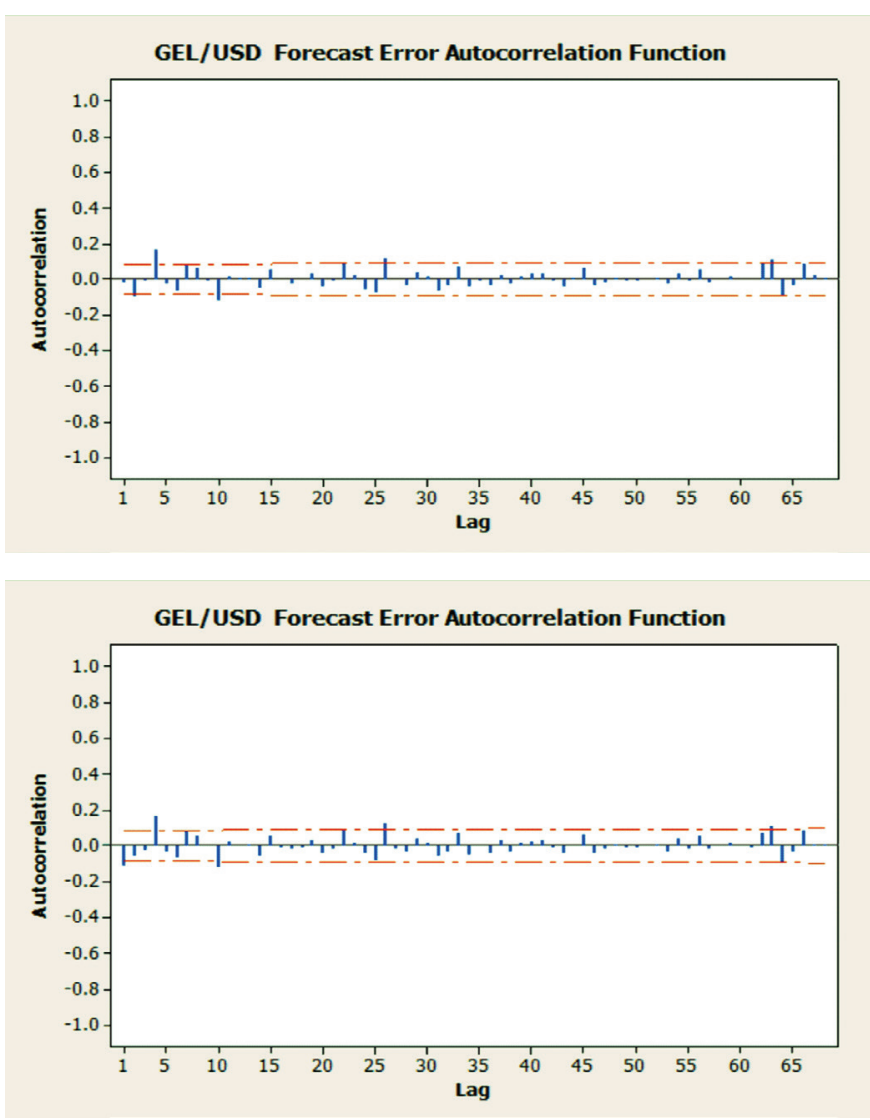

Figure 6: Residuals Plot Versus Fits

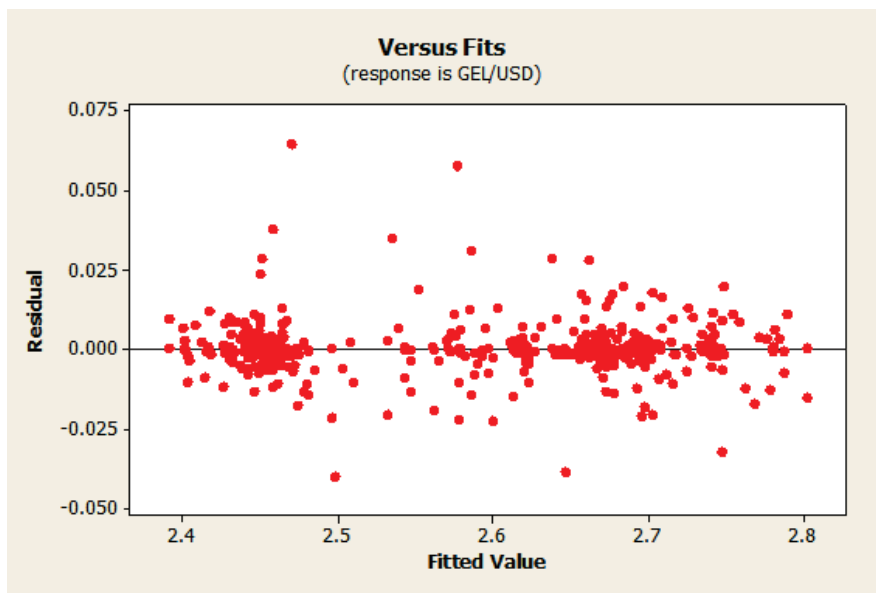

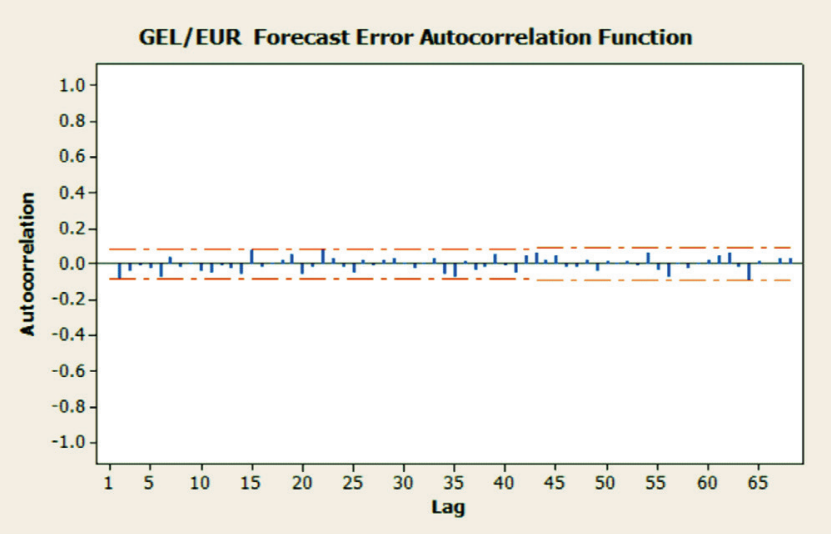

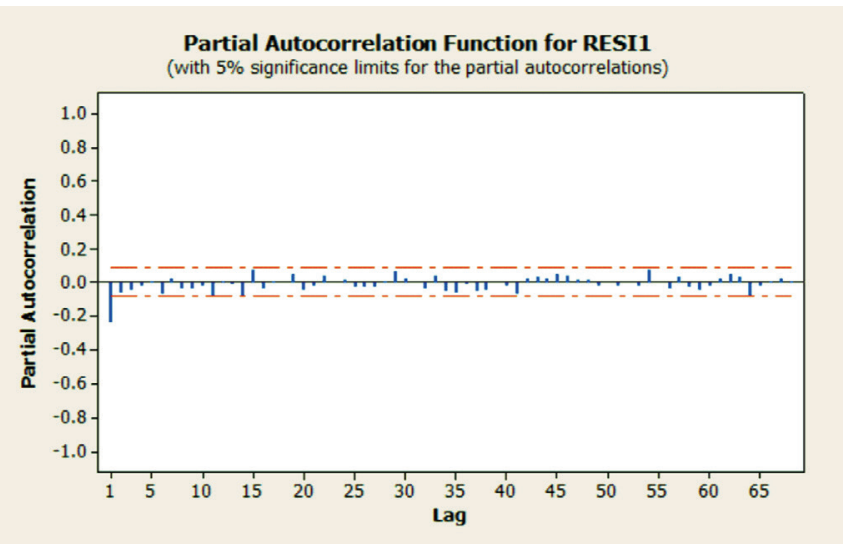

As the Figure 5 shows, the autocorrelation coefficients are close to the conclusion that the autocorrelation coefficients are not significant. Following figure (Figure 6) represents the plots of residuals versus predicted values for our estimated model and it also supports the conclusion about residuals autocorrelation.

\section{ARIMA MODELS IN FORECASTING EXCHANGE RATES}

Box-Jenkins (B-J) models are known as Auto Regressive Integrated Moving Average(ARIMA)(Box, G. E. P., and G. M. Jenkins, 1970). These models are one of the most important and widely used linear time series models (Michael, K., 2003). Time series models are generally not based on any underlying economic behavior. The ARIMA procedure is carried out on stationary data. These models typically relate a dependent variable to its past and to random errors that may be serially correlated. The widely used time series model is the ARIMA (p, d, q) process (Agung, 2009) Time Series Data Analysis Using EViews. Singapore: John Wiley \& Sons (Asia) Pte Ltd.[1]. ARIMA is powerful tool for forecasting 
currency exchange rates. One part of $\operatorname{ARIMA}(p, d, q)$ model is AR (autoregressive part), second part - I (integrated part), and third- MA (moving average part). In forecasting form, the general ARIMA (p, q) model selected can be expressed as follows:

$$
Y_{t}=\mu+\phi_{1} Y_{t-1}+\phi_{2} Y_{t-2}+\cdots+\phi_{p} Y_{t-p}-\omega_{1} \varepsilon_{t-1}-\omega_{2} \varepsilon_{t-2}-\cdots-\omega_{t-q} \varepsilon_{t-q}
$$

The key component of the ARIMA model is to determine $p$ and $q$. Where the order $p$ and $q$ of the model indicate how many previous times of data and errors we use to predict the present time. The shapes of ACF and PACF can help in determining these parameters and some statistical packages have tools helping to do this. When, as Figure 1 indicates, the time series is not stationary, it may be converted to a stationary series by differencing $\left(y_{t}=Y_{t}-Y_{t-1}\right)$ and after this transformation of time series $Y_{t}$ will be replaced by $y_{t}$. In this case, when $\left.\mathrm{d}=1\right)$, the ARIMA (p, $\left.1, q\right)$ is

$$
y_{t}=\mu+\phi_{1} y_{t-1}+\phi_{2} y_{2}+\cdots+\phi_{p} y_{t-p}-\omega_{1} \varepsilon_{t-1}-\omega_{2} \varepsilon_{t-2}-\cdots-\omega_{t-q} \varepsilon_{t-q}
$$

The sample autocorrelation (ACF) and partial-autocorrelation (PACF) correlograms were used (Figure 7) to identify autoregressive term and moving average term. Having chosen a particular ARIMA model, and having estimated its parameters, the adequacy of the model is checked by analyzing the residuals. If the residuals are white noise, it means that the model is acceptable, otherwise residuals goto model identification step.

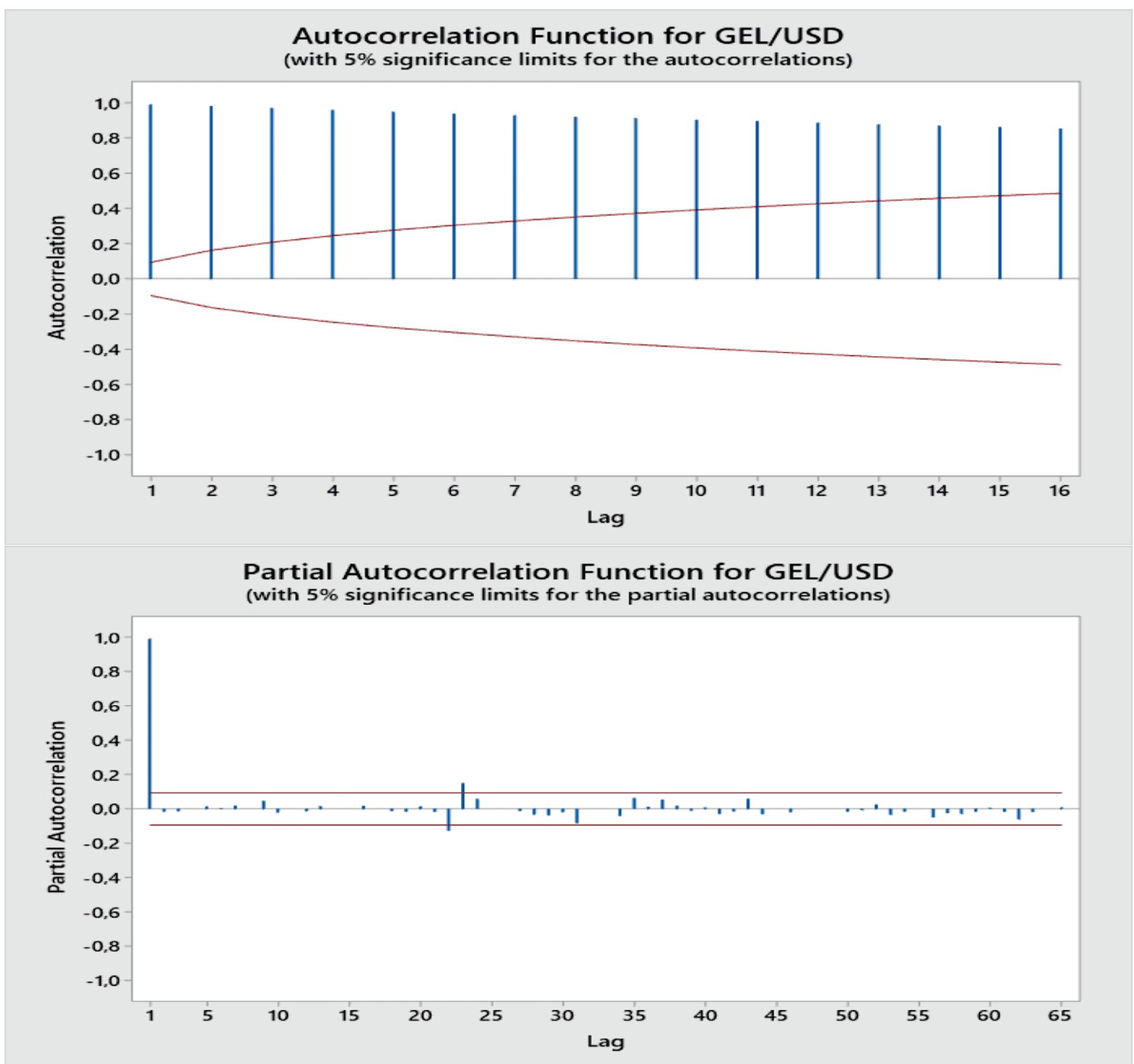

Figure 7 
These two figures indicate that the ACF and PACF coefficients are significant. Our decision regarding various orders of autoregressive $(p)$ and moving average $(q)$ based on analysis of the residuals by iterative procedures of model. In this process we kept integrated term $(d)$ as order 1 . We have tested the numbers of ARIMA models and only listed in table6models residuals had noisy pattern and estimated models parameters are significant. The results of this process are shown in Table 6 and it reports the values of $\mathrm{AIC}^{2}$ and $\mathrm{BIC}^{3}$ for various orders of ARIMA model for GEL against USED and EUR. The AIC and BIC values represented in the Table 4 were by using following formulae's:

$$
\begin{aligned}
& A I C=\ln \hat{\sigma}^{2}+\frac{2}{n} r \\
& B I C=\ln \hat{\sigma}^{2}+\frac{\ln n}{n} r
\end{aligned}
$$

Where: In = the natural log; $\hat{\sigma}^{2}=$ the residual sum of squares divided by the number of observation; $\mathrm{n}=$ the number of

\begin{tabular}{|c|c|c|c|c|}
\hline \multicolumn{5}{|c|}{ 1. Estimates of ARIMA $(2,1,2)$ Parameters for GEL/USD } \\
\hline Type & Coef & SE Coef & T & $P$ \\
\hline AR 1 & 0.714 & 0.1587 & 4.5 & 0 \\
\hline MA 1 & 0.6896 & 0.1608 & 4.29 & 0 \\
\hline MA 2 & 0.0993 & 0.047 & 2.11 & 0.035 \\
\hline Constant & $-4.3 \mathrm{E}-06$ & 0.000125 & -0.03 & 0.973 \\
\hline \multicolumn{5}{|c|}{ Differencing: 1 regular difference } \\
\hline \multicolumn{5}{|c|}{ Number of observations: Original series 535, after differencing 534} \\
\hline Residuals: $\mathrm{SS}=$ & 0.098419 & \multicolumn{3}{|c|}{ (backforecasts excluded) } \\
\hline $\mathrm{MS}=$ & 0.000186 & $\mathrm{DF}=$ & 530 & \\
\hline \multicolumn{5}{|c|}{ Modified Box-Pierce (Ljung-Box) Chi-Square statistic } \\
\hline Lag & 12 & 24 & 36 & 48 \\
\hline Chi-Square & 5.5 & 19.2 & 26.7 & 36.6 \\
\hline $\mathrm{DF}$ & 8 & 20 & 32 & 44 \\
\hline P-Value & 0.704 & 0.512 & 0.731 & 0.778 \\
\hline \multicolumn{5}{|c|}{ 2. Estimates of ARIMA $(1,1,2)$ Parameters for GEL/EUR } \\
\hline Type & Coef & SE Coef & T & $P$ \\
\hline AR 1 & 0.714 & 0.1587 & 4.5 & 0 \\
\hline MA 1 & 0.6896 & 0.1608 & 4.29 & 0 \\
\hline MA 2 & 0.0993 & 0.047 & 2.11 & 0.035 \\
\hline Constant & $-4.3 \mathrm{E}-06$ & 0.000125 & -0.03 & 0.973 \\
\hline \multicolumn{5}{|c|}{ Differencing: 1 regular difference } \\
\hline \multicolumn{5}{|c|}{ Number of observations: Original series 535, after differencing 534} \\
\hline Residuals: $\mathrm{SS}=$ & 0.098419 & \multicolumn{3}{|c|}{ (backforecasts excluded) } \\
\hline $\mathrm{MS}=$ & 0.000186 & $\mathrm{DF}=$ & 530 & \\
\hline \multicolumn{5}{|c|}{ Modified Box-Pierce (Ljung-Box) Chi-Square statistic } \\
\hline Lag & 12 & 24 & 36 & 48 \\
\hline Chi-Square & 5.5 & 19.2 & 26.7 & 36.6 \\
\hline DF & 8 & 20 & 32 & 44 \\
\hline P-Value & 0.704 & 0.512 & 0.731 & 0.778 \\
\hline
\end{tabular}
observations; $r$ = the total number of parameters in the ARIMA model. The estimates of these three models are:

\footnotetext{
${ }^{2}$ The information criterion of Akaike (Akkaike, H. 1974)

${ }^{3}$ The Bayesian information criterion of Scherz (Sachwarz, G. 1978)
} 


\begin{tabular}{|c|c|c|}
\hline \multicolumn{3}{|c|}{$\begin{array}{l}\text { Table 5: The Accuracy Measures of } \\
\text { the ARIMA Models }\end{array}$} \\
\hline & $\begin{array}{c}\text { ARIMA(2,1,) } \\
\text { GEL/USD }\end{array}$ & $\begin{array}{c}\text { ARIMA }(1,1,2) \\
\text { GEL/EUR }\end{array}$ \\
\hline MAPE & $2.480 \mathrm{E}-05$ & 6.13238E-05 \\
\hline MAD & $4.384 \mathrm{E}-03$ & $8.825 \mathrm{E}-03$ \\
\hline MSD & $6.405 \mathrm{E}-05$ & $1.843 \mathrm{E}-04$ \\
\hline FCPCD & $70 \%$ & $72 \%$ \\
\hline
\end{tabular}

\begin{tabular}{|l|c|c|c|c|}
\hline \multicolumn{5}{|c|}{ Table 6: AIC and BIC Value for Various Orders of ARIMA } \\
\hline ARIMA(p, d, q) & \multicolumn{2}{|c|}{ GEL/USD } & \multicolumn{2}{c|}{ GEL/EUR } \\
\hline & AIC & BIC & AIC & BIC \\
\hline ARIMA $(1,1,0)$ & -9.60701 & -9.58296 & -8.57106 & -8.55263 \\
\hline ARIMA $(1,1,1)$ & -9.61765 & -9.59361 & -8.57981 & -8.54775 \\
\hline ARIMA $(2,1,0)$ & -9.62318 & -9.59914 & -8.58125 & -8.54919 \\
\hline ARIMA $(2,1,1)$ & -9.62373 & -9.59969 & -8.58149 & -8.54141 \\
\hline ARIMA $(1,1,2)$ & -9.62042 & -9.59637 & -8.58206 & -8.54198 \\
\hline ARIMA $(2,1,2)$ & -9.64648 & -9.62243 & -8.57875 & -8.53065 \\
\hline
\end{tabular}

Lowest AIC or BIC value is considered as best fit of the model. According these criteria the best would be ARIMA (2, 1, 2) for GEL/USD andARIMA $(1,1,2)$ - for GEL/EUR. By criteria FCPCD, Table 7, the best models are not the only one. There are: $\operatorname{ARIMA}(1,1,0)$ and $\operatorname{ARIMA}(2,1,2)$ for GEL/USD; $\operatorname{ARIMA}(2,1,1)$,ARIMA $(1,1,2)$ and ARIMA $(2,1,2+$ for GEL/EUR by FCPCD criteria.

Table 7: FCPCDValue for Various Orders of ARIMA

\begin{tabular}{|l|c|c|}
\hline ARIMA(p, $\mathbf{d}, \mathbf{q})$ & GEL/USD & GEL/EUR \\
\hline $\operatorname{ARIMA}(1,1,0)$ & $70 \%$ & $67 \%$ \\
\hline $\operatorname{ARIMA}(1,1,1)$ & $69 \%$ & $68 \%$ \\
\hline $\operatorname{ARIMA}(2,1,0)$ & $69 \%$ & $68 \%$ \\
\hline $\operatorname{ARIMA}(2,1,1)$ & $68 \%$ & $72 \%$ \\
\hline $\operatorname{ARIMA}(1,1,2)$ & $69 \%$ & $72 \%$ \\
\hline $\operatorname{ARIMA}(2,1,2)$ & $70 \%$ & $72 \%$ \\
\hline
\end{tabular}

The below Figure 9 plots the predicted exchange rates usingthe best ARIMA we have determined - ARIMA (2, 1, 2) for GEL/USD, (1, 1, 2)and for GEL/EUR.

\section{THE RESULTS AND COMPARISON OF MODELS}

In this section we will compare the models used above. AIC and BIC can be used for comparing and selecting model. The calculation results are represented the Table 8.

Table 8: Values of Model Selection Criteria: AIC and BIC

\begin{tabular}{|c|c|c|c|c|c|}
\hline & & MA & ES & DES & ARIMA \\
\hline \multirow{2}{*}{ GEL/USD } & AIC & -7.4491 & -8.0297 & -8.0190 & -9.6465 \\
\cline { 2 - 6 } & BIC & -7.4475 & -8.0282 & -8.0163 & -9.6224 \\
\hline \multirow{2}{*}{ GEL/EUR } & AIC & -7.5970 & -7.4535 & -7.2467 & -8.5821 \\
\cline { 2 - 6 } & BIC & -7.5954 & -7.4508 & -7.2440 & -8.5420 \\
\hline
\end{tabular}

Table 9: Correct Predicted Change Direction- FCPCD

\begin{tabular}{|c|c|c|c|c|c|c|}
\hline & SMA & EMA & WMA & SES & HES & ARIMA \\
\hline GEL/USD & $72 \%$ & $58 \%$ & $66 \%$ & $75 \%$ & $77 \%$ & $70 \%$ \\
\hline GEL/EUR & $73 \%$ & $65 \%$ & $68 \%$ & $65 \%$ & $69 \%$ & $72 \%$ \\
\hline
\end{tabular}

Table 9 shows the forecasted correct number of exchange rate change directions. In this point of view,the ARIMA models catch correct change directions for all considered currency rates. The results of exponential smoothing and ARIMA models forecasting are presented in Figure 8.As Table 6 shows, by criteria AIC and BIC ARIMA models are leading, while by criteria FCPCD MA models are leading (Table 7). In these models we usedthe most recent exchange rates, and calculated the short-run MA. This model with combination to Long-run MA, can be used to generate currency trading signals for making buy or sell decisions.

${ }^{4}$ ACF and PACF for all models are not significant. 
Figure 8: ARIMA Models Forecasting Results from ARIMA $(2,1,2)-$ GEL/USD and ARIMA $(1,1,2)$ - GEL/EUR
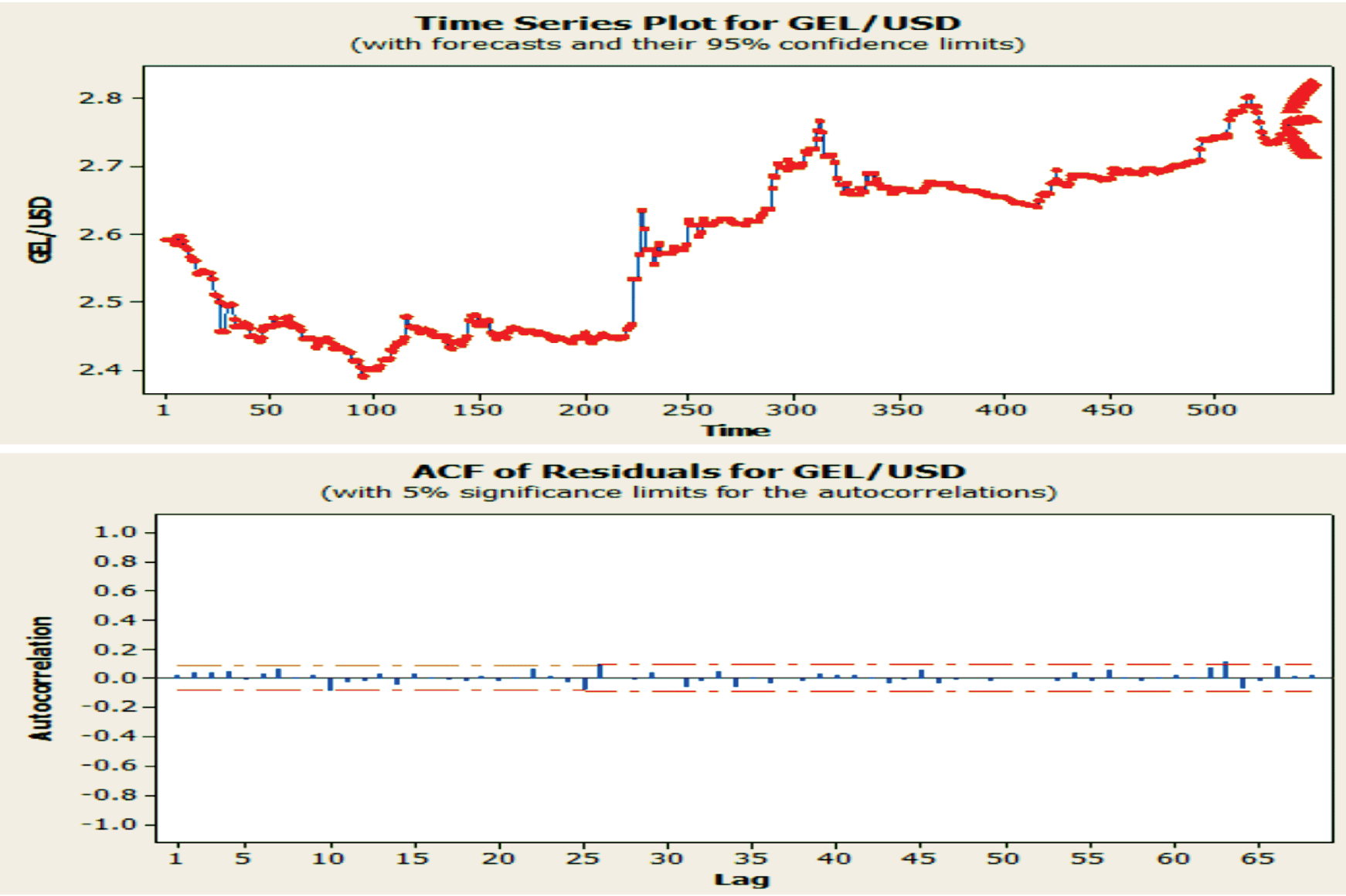

Time Series Plot for GEL/EUR
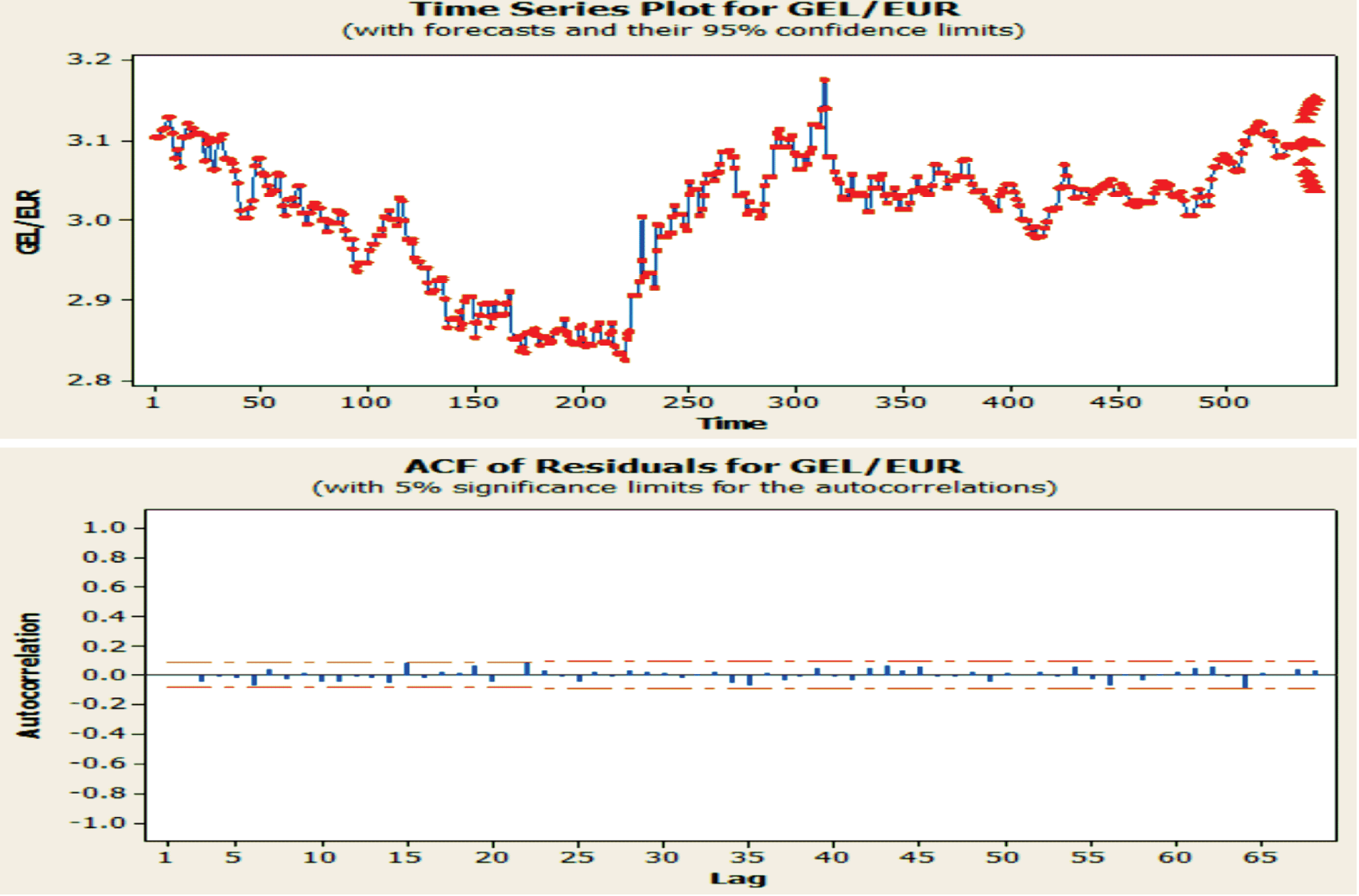

Figure 8 


\section{CONCLUSION}

All simple moving averages are lagging indicators and have tendency to be "behind" the price. When the exchange rate is trending down the SMA's rates remain above the real figure and if exchange rate is trending up, SMA would be below the real figure. However, in short-run, SMA the most quickly catches changing behavior of exchange rates. Accordingly, as indicated in Table 8, SMA gave the best results in FCPCD. Weighted moving average models assign the nearest data of time series more weight and, as a rule, more accurately reflects the results of the change. But, in our case, this was not the case and SMA was far better at guessing the direction of change.

Exponential moving average reduces the lag in the SME. Predicted exchange rates do not tend to be lower or higher for some period than the real exchange rate. Although, despite this advantage and much better in accuracy measures, it falls far behind in recognizing change direction - FCPCD.These models work well even when the time series contains a moderate trend. When there are much stronger and long period trending tendency, as expected, there would be much better rendered the Holt Exponential Smoothing than simple exponential moving average.The time series may change its be- havior and to reflect this change this class of adoptive model's parameters must be updated timely. In order to maintain model adequacy and to obtain good result, it is necessary to make careful calculations of new parameters and include sufficient number of previous data.

ARIMA Models: All three selected models (ARIMA (2, 1, 2) for GEL / USD and ARIMA (1, 1, 2) - GEL / EUR have minimum AIC and BIC, and also have the minimum MSD. One order $(d=1)$ difference turned out sufficient to transform the initial non-stationary time series into stationary. It is important to note that these models respond quickly to changes and also doing relatively well in predicting the direction of currency exchange rates. As the results show, ARIMA has the advantage of medium term currency forecasting. However, we have to keep in mind the fact that ARIMA model is based on the assumption that there is a linear relationship between current and previous values. In the case of nonlinearity,ARIMA approximation would not be desirable for accuracy and therefore inadequate. As it is well known, the likelihood of a linear process being nonlinear is likely not to be zero, so the linearity hypothesis of this dependence should be tested periodically and, if appropriate, linear models should be replaced with nonlinear models(Khashei, M. , M. 2011).

\section{REFERENCE:}

1. Agung IG (2009). Time Series Data Analysis Using EViews. Singapore: John Wiley \& Sons (Asia) Pte Ltd.

2. Akkaike, H. (1974). A New Look at the Statistical Model Identification. IEEE Transactions Automatic Control 19; $716-723$.

3. Box, G. E. P., and G. M. Jenkins, (1970).Time Series Analysis, Forecasting, and Control. Holden Day, San Francisco.

4. Khashei, M. and Bijari, M. (2011). A Novel Hybridization of Artificial Neural Networks and ARIMA Models for Time Series Forecasting. Applied Soft Computing, 11, 2664-2675.

5. Michael, K. Evans. (2003). Practical Business Forecasting, Blackwell Publishers, 225-269.

6. Sachwarz, G. (1978). Estimating the Dimension of a Model. Annals of Statistics 6: $461-464$. 


\title{
TIME SERIES MODELS FOR FORECASTING EXCHANGE RATES
}

\author{
GIVI LEMONJAVA \\ Associated Professor, \\ University of Georgia, Georgia \\ Givi@tbcbank.com.ge
}

\section{KEYWORDS: EXCHANGE RATE, FORECASTING EXCHANGE RARE, TIME SERIES ANALYSIS, ARIMA, MOVING} AVERAGE MODEL, SIMPLE AND DOUBLE EXPONENTIAL SMOOTHING MODELS.

For citation: Lemonjava, G. (2019). Time Series Models for Forecasting Exchange Rates, Globalization And Business, №8, pp. $149-160$. https://doi.org/10.35945/gb.2019.08.020

\section{SUMMARY}

This paper investigates the behavior of daily exchange rate of the Georgian Currency LARI (GEL) exchange rate against the USD and EUR. To forecast exchange rates there are numerous models, which tend from very simple to very complicated models for analysis of GEL/USD and GEL/EUR time series variable. The objective of this paper is to compare the performance of individual time series models for predicting exchange rates. We will investigate the application of following time series analysis models: moving average, exponential smoothing, double exponential smoothing adjusted for trend, time-series decomposition models, and ARIMA class models. The forecasting ability of these models is subsequently assessed using the symmetric loss functions which are the Mean Absolute Percentage Error (MAPE), the Mean Absolute deviation (MAD), and the Mean Squared error /deviation (MSE/MSD). In some cases, predicting the direction of exchange rate change may be valuable and profitable. Hence, it is reasonable to look at the frequency of the correct predicted direction of change by used models, for short - FCPCD.

An exchange rate represents the price of one currency in terms of another. It reflects the ratio at which one currency can be exchanged with another currency. Exchange rates forecasting is a very important and challenging subject of finance market, to determine optimal government policies as well as to make business decisions. This is important for all that firms which having their business spread over different countries or for that which raise funds in different currency. Business people mainly use exchange rates forecasting results in following types of decisions like choice currency for invoicing, pricing transactions, borrowing and landing curren- cy choice, and management of open currency positions. The forex market is made up of banks, commercial companies, central banks, investment management firms, hedge funds, and retail forex brokers and investors. Forecasting the shortrun fluctuations and direction of change of the currency exchange rates is important for all these participates.

The main goal of this study is to forecast of future exchange rate trends by using currency rates time-series, representing past trends, patterns and waves. The monetary policy of the National Bank of Georgia since 2009 has been followed the inflation targeting regime, where exchange rate regime is floating - change of exchange rate is free. The official exchange rate of the Georgian GEL against the USD is calculated each business day. The official exchange rate of GEL against USD is calculated as the average weighted exchange rate of the registered spot trades on the interbank market functioning within the Bloomberg trade platform. Then, the official exchange rate of GEL against other foreign currencies is determined according to the rate on international markets on the basis of cross-currency exchange rates.

All simple moving averages are lagging indicators and have tendency to be "behind" the price.Exponential moving average reduces the lag in the SME. Predicted exchange rates do not tend to be lower or higher for some period than the real exchange rate. Although, despite this advantage and much better in accuracy measures, it falls far behind in recognizing change direction - FCPCD. As concerns ARIMA Models: All three selected models (ARIMA $(2,1,2)$ for GEL / USD and ARIMA $(1,1,2)$ - GEL / EUR have minimum AIC and BIC, and also have the minimum MSD. One order $(d=1)$ difference turned out sufficient to transform the initial non-stationary time series into stationary. 